\title{
Kelvin probe force microscopy of the nanoscale electrical surface potential barrier of metal/semiconductor interfaces in ambient atmosphere
}

\author{
Petr Knotek ${ }^{1}$, Tomáš Plecháček ${ }^{2}$, Jan Smolík ${ }^{1}$, Petr Kutálek ${ }^{*} 2 \S$, Filip Dvořák ${ }^{3}$, \\ Milan Vlček ${ }^{4}$, Jiř́ Navrátil ${ }^{5}$ and Čestmír Drašar ${ }^{5}$
}

\author{
Full Research Paper \\ Address: \\ 1University of Pardubice, Faculty of Chemical Technology, \\ Department of General and Inorganic Chemistry, Studentská 573, 532 \\ 10 Pardubice, Czech Republic, ${ }^{2}$ University of Pardubice, Faculty of \\ Chemical Technology, Joint Laboratory of Solid State Chemistry, \\ Studentská 84, 53210 Pardubice, Czech Republic, ${ }^{3}$ University of \\ Pardubice, Faculty of Chemical Technology, Center of Materials and \\ Nanotechnologies, Studentská 95, 532 10, Pardubice, Czech \\ Republic, ${ }^{4}$ Institute of Macromolecular Chemistry of the Academy of \\ Sciences of the Czech Republic v.v.i., Heyrovsky sq. 2, 12006 \\ Prague, Czech Republic and ${ }^{5}$ University of Pardubice, Faculty of \\ Chemical Technology, Institute of Applied Physics and Mathematics, \\ Studentská 95, 532 10, Pardubice, Czech Republic \\ Email: \\ Petr Kutálek* - petr.kutalek@upce.cz \\ * Corresponding author \\ § Tel.: +420 466036155; fax: +420 466036011 \\ Keywords: \\ Kelvin probe atomic force microscope; nanoinclusion; Schottky \\ barrier; thermoelectric materials; work function \\ Beilstein J. Nanotechnol. 2019, 10, 1401-1411. \\ doi:10.3762/bjnano.10.138 \\ Received: 04 April 2019 \\ Accepted: 18 June 2019 \\ Published: 15 July 2019 \\ Associate Editor: T. Glatzel \\ (c) 2019 Knotek et al.; licensee Beilstein-Institut. \\ License and terms: see end of document.
}

\footnotetext{
Abstract

This study deals with the preparation and characterization of metallic nanoinclusions on the surface of semiconducting $\mathrm{Bi}_{2} \mathrm{Se}_{3}$ that could be used for an enhancement of the efficiency of thermoelectric materials. We used Au forming a 1D alloy through diffusion (point nanoinclusion) and Mo forming thermodynamically stable layered $\mathrm{MoSe}_{2}$ nanosheets through the reaction with the $\mathrm{Bi}_{2} \mathrm{Se}_{3}$. The Schottky barrier formed by the 1D and 2D nanoinclusions was characterized by means of atomic force microscopy (AFM). We used Kelvin probe force microscopy (KPFM) in ambient atmosphere at the nanoscale and compared the results to those of ultraviolet photoelectron spectroscopy (UPS) in UHV at the macroscale. The existence of the Schottky barrier was demonstrated at $+120 \mathrm{meV}$ for the Mo layer and $-80 \mathrm{meV}$ for the Au layer reflecting the formation of $\mathrm{MoSe}_{2}$ and $\mathrm{Au} / \mathrm{Bi}_{2} \mathrm{Se}_{3}$ alloy, respectively. The results of both methods (KPFM and UPS) were in good agreement. We revealed that long-time exposure (tens of seconds) to the electrical field leads to deep oxidation and the formation of perturbations greater than $1 \mu \mathrm{m}$ in height, which hinder the $I-V$ measurements.
} 


\section{Introduction}

Increasing energy demand and the negative effects of current energy technologies on the environment lead to increased interest in alternative energy technologies. Thermoelectric (TE) devices, utilizing TE phenomena, i.e., the Seebeck and the Peltier effect, can be considered solid-state heat engines. The former enables direct waste heat conversion into electrical energy very elegantly (no moving parts, long-term stability, maintenance-free, silent). Unfortunately, one of the limiting factors of this technology is still poor conversion efficiency. The conversion efficiency of the material could be expressed in terms of figure-of-merit, ZT, defined as dimensionless quantity $\mathrm{ZT}=S^{2} \cdot \sigma \cdot T / \kappa$, where $S$ is the thermopower (Seebeck coefficient), $\sigma$ is the electrical conductivity, $T$ is the absolute temperature and $\kappa$ is the thermal conductivity. There were many concepts for enhancement of ZT values, e.g., advanced TE bulk compounds of more complex crystal structures [1], low-dimensional material systems [2] or nanostructured advanced bulk materials [3]. Recently the concept of multi-phase nanocomposites (NCs), i.e., an incorporation of second-phase nanoinclusions/nanoparticals (NIs/NPs) into the bulk semiconducting matrices has been proposed [4-6] and supported in theoretical works [7-9]. Such NIs or NPs are able to enhance ZT via a reduction of the thermal conductivity by phonon scattering [1014], by modulated carrier doping or by the carrier energy filtering effect [15-17]. The potential energy barrier connected with a metallic NP (Schottky barrier) or a multi-phase interface could scatter low-energy electrons more effectively than highenergy electrons [18]. This, in turn, results in an enhancement of the Seebeck coefficient with virtually no harm to other transport parameters.

The characterization of NIs or NPs in TE materials is realized most frequently by the different modes of atomic force microscopy (AFM): i) by comparing the conductivity/resistivity (CAFM) or $I-V$ curves measurement in the direct-contact of the conductive tip and the material [19-21]; ii) by mapping of the different surface contact potential values by Kelvin probe force microscopy (KPFM) in the semicontact mode [19,22-25], or iii) by measuring the differences in thermal conductivity by scanning thermal microscopy (SThM) $[19,20,26]$. Shape, size, homogeneity of distribution and chemical composition as the basic characteristics are studied by using electron microscopy (SEM+TEM), although there is a high probability that the NPs diffuse into the TE matrix due to the e-beam interaction. Hence, these characterizations are also performed by using scanning tunneling microscopy (STM) $[27,28]$ or by using AFM in the semicontact mode. The latter enables a describtion not only of the topography (size and shape) but also a detection of the changes in density, stiffness and adhesion of NPs $[20,21,24,29,30]$.
In the present study we demonstrate that the Schottky barrier (surface contact potential) value and the polarity can be controlled by the barrier-forming metal NPs (Au, Mo) and can reflect their different chemical behavior with the $\mathrm{Bi}_{2} \mathrm{Se}_{3}$ matrix. These metals were selected due to the different interaction with the matrix, as $\mathrm{Au}$ can diffuse to the $\mathrm{Bi}_{2} \mathrm{Se}_{3}$ forming $\mathrm{Au} / \mathrm{Bi}_{2} \mathrm{Se}_{3}$ alloy and NIs in the shape of a semispherical defect, whereas Mo reacts with the matrix and forms thermodynamically more stable layered $\mathrm{MoSe}_{2}$ in the shape of nanosheets.

\section{Experimental}

Single crystalline $\mathrm{Bi}_{2} \mathrm{Se}_{3}$ samples were grown by heating stoichiometric mixtures of the pure elements obtained from SigmaAldrich, i.e., $5 \mathrm{~N}$ Bi and $5 \mathrm{~N}$ Se. The crystal growth was performed by cooling in a horizontal furnace from $1073 \mathrm{~K}$ to $823 \mathrm{~K}$ at a rate of $6 \mathrm{~K}$ per hour. The crystals were then annealed at $823 \mathrm{~K}$ for $350 \mathrm{~h}$ and quenched in air. This free-melt crystallization (FMC) procedure produces single crystals of 10-20 mm in length, 3-6 mm in width and up to $3 \mathrm{~mm}$ in thickness [31]. The surface of freshly cleaved layered $\mathrm{Bi}_{2} \mathrm{Se}_{3}$ single crystals was used as a substrate. The samples for the AFM measurement, Au nanoparticles (NPs) and thin films of gold or molybdenum, were prepared via DC sputtering in a SEM Coating System (Bio-Rad) in Ar atmosphere ( $p \approx 20 \mathrm{~Pa}, I=18 \mathrm{~mA}$, $U=1.4 \mathrm{kV}$ ) from pure metal sheets (Mo $4 \mathrm{~N}, \mathrm{Au} 4 \mathrm{~N})$. For preparing separated $\mathrm{Au}$ nanoparticles under the same sputtering conditions, however, a stainless steel mask (system of $100 \times 500 \mu \mathrm{m}^{2}$ holes, $200 \mathrm{holes} / \mathrm{cm}^{2}$ ) between the substrate and target had to be used to decrease the plasma intensity.

The topography, phase shift image, Kelvin probe force microscopy and $I-V$ characteristics were measured by the AFM SolverPro M, Nt-MDT (Russia) with a resolution of $512 \times 512$ pixels. The HA_NC tips (resonant frequency $140 \mathrm{kHz}$, force constant $3.5 \mathrm{~N} / \mathrm{m}$ ) were used for measuring the metal layer thickness by the scratch method and phase contrast [30,32], while conductive NSG01/TiN tips $(150 \mathrm{kHz}, 5.1 \mathrm{~N} / \mathrm{m})$ were used for Kelvin probe force measurements and contact CSG-10/Pt tips $(22 \mathrm{kHz}, 0.11 \mathrm{~N} / \mathrm{m})$ for recording $I-V$ characteristics [33,34] for 10 replicas from an identical point without delay; see the corresponding references above for other experimental details. The set-point was stabilized in the range of $40-50 \%$ and the scanning frequency of $0.5 \mathrm{~Hz}$ was used, if not mentioned otherwise. A separation of the topographical signal and the $V_{\mathrm{CPD}}$ (the contact potential difference) measurement was achieved by the modulation of the $V_{\mathrm{AC}}$ at a frequency higher than the bandwidth of the topography feedback system. The topography was measured by the oscillation at the first resonance frequency of the AFM tip, and $V_{\mathrm{CPD}}$ was measured by the amplitude of the oscillation at the second resonance fre- 
quency of the AFM tip [35,36]. It also has to be noted that all measurements were carried out at room temperature.

Photodiffusion of the metal into $\mathrm{Bi}_{2} \mathrm{Se}_{3}$ was enabled by means of a Ronchi ruling (non-transparent $\mathrm{Cr}$ lines on the $\mathrm{SiO}_{2}$ substrate) with a density of 2000 lines per millimeter (period $500 \mathrm{~nm}$ ) as a photomask. The material was illuminated with a UV light source LC08 (Hamamatsu) emitting at wavelengths of 310 and $360 \mathrm{~nm}$; total intensity $0.8 \mathrm{~W} / \mathrm{cm}^{2}$ for $60 \mathrm{~s}$ [37,38]. The e-beam diffusion was realized by a SEM JEOL JSM 5500-LV in an of area $8 \times 10 \mu \mathrm{m}^{2}$ with an acceleration voltage of $20 \mathrm{kV}$ (which results in a penetration depth of the electrons of $1 \mu \mathrm{m}$ into $\mathrm{Bi}_{2} \mathrm{Se}_{3}$ ) for a period of maximally $360 \mathrm{~s}$.

The work function (WF) was determined by utraviolet photoelectron spectroscopy (UPS) using a helium gas discharge source with He I radiation $(h v=21.22 \mathrm{eV})$. All UPS measurements were performed in an UHV apparatus (ESCA 2SR, Scienta-Omicron) with a base pressure below $1 \times 10^{-9}$ mbar.
The spectra were calibrated using the Fermi edge of sputtercleaned Au as reference. During the measurements, a bias of $-10 \mathrm{~V}$ was applied to the sample in order to cut off secondary electrons generated in the analyzer. The work function of the sample was calculated as WF $=h v E_{\text {cut-off, where } E_{\text {cut-off }} \text { was }}$ determined from the intersection of the linear extrapolation of the secondary-electron cut-off (SECO) with the background. All samples were sputtered with argon ions using a scanning focused ion beam source in order to remove surface contaminants. A monoatomic argon ion source was utilized with energy of $2 \mathrm{keV}$, ion current $10 \mu \mathrm{A}$, raster area $1 \times 1 \mathrm{~mm}^{2}$ and sputtering time $30 \mathrm{~s}$.

\section{Results and Discussion \\ Separated metal nanoparticles on the substrate}

In TE materials the NIs applicable for an increase of their profitability/efficiency should be present as $1 \mathrm{D}$ materials or 2D layers. The aim of the characterization of the NIs is the proof of
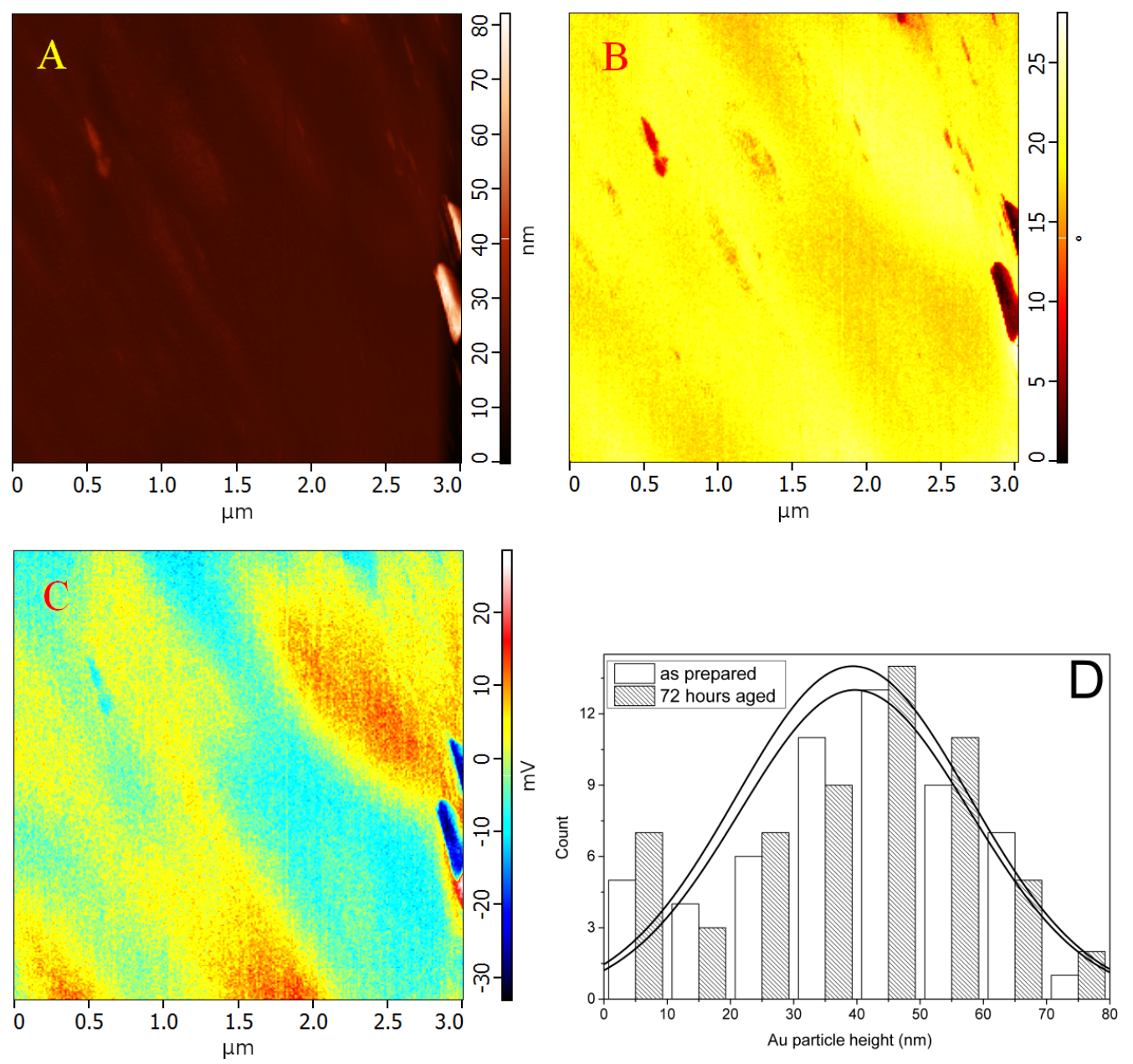

Figure 1: (A) Topographical and (B) phase-shift image, and (C) surface contact potential map of Au nanoparticles on $\mathrm{Bi}_{2} \mathrm{Se}_{3}$ (as prepared); (D) histogram of the Au NP height distribution for the as-prepared sample and after $72 \mathrm{~h}$. 
their presence, the description of their shape and of their electrical behavior in contrast to the unaffected matrix material. We used $\mathrm{Bi}_{2} \mathrm{Se}_{3}$ as a standard material because of its well-defined layered structure with sub-nanometer roughness similar to mica or highly oriented pyrolytic graphite (HOPG). The electrical conductivity and mechanical stiffness of $\mathrm{Bi}_{2} \mathrm{Se}_{3}$ allow for the measurement with high-intensity electrical fields $(10 \mathrm{~V} / 30 \mathrm{~nm})$ without damaging the topmost layer.

The Au particles were dc-sputtered onto the $\mathrm{Bi}_{2} \mathrm{Se}_{3}$ substrate and the surface was immediately measured by means of AFM. The particles exhibited a height ranging from 5 to $70 \mathrm{~nm}$. The height distribution (with the maximal population at ca. $40 \mathrm{~nm}$ ) and the FWHM did not change within $72 \mathrm{~h}$ after preparation (Figure 1A and Figure 1D). The stability of the histograms over 3 days led us to believe that during this time interval there is only negligible diffusion of the $\mathrm{Au}$ NPs into the $\mathrm{Bi}_{2} \mathrm{Se}_{3}$ substrate. The material of the particles was mechanically different as observed on the phase shift image (Figure 1B) due to local changes in adhesion, density, and stiffness [30]. This fact demonstrates the difference between the NPs and the substrate, regardless of any artifacts of the sample preparation/measurement.

KPFM is a double-pass measurement technique, where the lift height between the first (topographical) and second (electrical) pass is an important parameter for the spatial resolution $[36,39,40]$. The tested lift heights were 10,30 and $50 \mathrm{~nm}$, and the optimal value was found to be $30 \mathrm{~nm}$ (Figure 1C). The KPFM image has a good contrast for a lift height of $30 \mathrm{~nm}$ and particles with a height less than $10 \mathrm{~nm}$ were detected in the map of the surface contact potential. A higher lift height led to a vanishing of the contrast and a lower value resulted in a decrease in reproducibility (data not shown). The results are in a good agreement with the KPFM contrast of nanodiamonds on a $\mathrm{Si}$ substrate, where the contrast even changed for the lower lift height (see Figure 10.2 in [41]). The atypical conductive TiN coating of the tip (instead of $\mathrm{Pt}, \mathrm{Au} \mathrm{Pt} / \mathrm{Ir}$ or Pt/Cr tips $[33,41$ 43]) was used because of the higher mechanical stability of the tips and in order to eliminate diffusion and other chemical interactions of the tip coating with the samples. The measured difference of the surface contact potential (Figure 1C) between $\mathrm{Au}$ particles and $\mathrm{Bi}_{2} \mathrm{Se}_{3}$ was not identical for all particles depended on the height of the particles. The height, i.e., the vertical distance between the top of the NP and the substrate and the contrast of the surface contact potential of Au particles (Figure 2A, B) were measured within the same line profile. Au NPs of greater height showed lower values of the surface contact potential according to the non-linear curve limited to a $\Delta$ surface contact potential between -50 and $-60 \mathrm{mV}$. This observation can be attributed to quantum size effects [36,44], which are accompanied by a change in the charge transfer from substrate to NPs $[45,46]$.

\section{Metal layers on $\mathrm{Bi}_{2} \mathrm{Se}_{3}$}

The dependence of the surface contact potential on the size of the separated Au nanoparticles theoretically allows for an optimization of the efficiency of TE materials. Our efforts to prepare separated Mo NPs on the $\mathrm{Bi}_{2} \mathrm{Se}_{3}$ surface was not successful. Because Mo has significantly higher melting/boiling points (bulk Mo $2623 / 4639{ }^{\circ} \mathrm{C}$, bulk Au $1064 / 2856{ }^{\circ} \mathrm{C}$ [47]) dc sputtering yielded homogeneous layers of Mo instead of separated NPs. In addition, the preparation from colloidal metallic NPs failed as the solvents or stabilizing agents as polyphosphates or vinylpyrrolidones [48] interacted with the uppermost $\mathrm{Bi}_{2} \mathrm{Se}_{3}$ layer, or residua of the organic solvents that were not evaporated under the vacuum changed the electrical behavior of the nanocomposite.
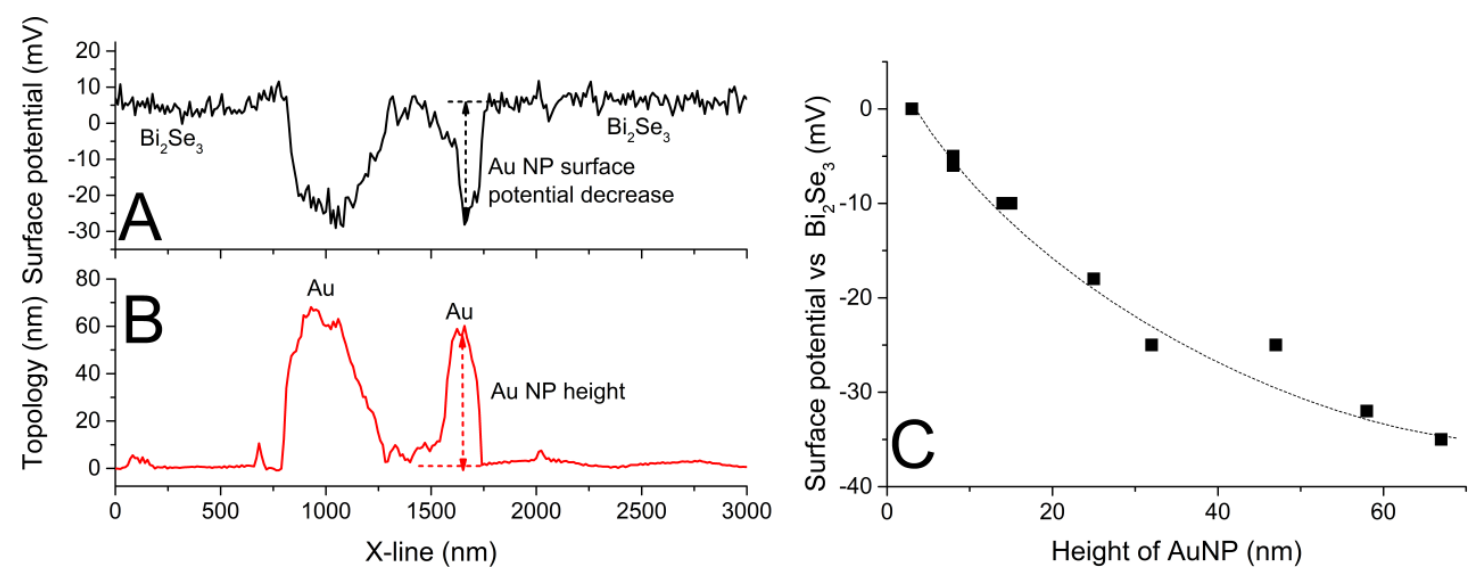

Figure 2: $(A, B)$ Determination of the surface contact potential decrease and the height of the Au NPs; (C) surface contact potential as a function of the Au NP height. 
An alternative way to study Schottky barriers at the nanoscale is to prepare a metallic layer on the $\mathrm{Bi}_{2} \mathrm{Se}_{3}$ surface and characterize such a nanocomposite. $I-V$ spectroscopy is typically used for the determination of Schottky barriers $[25,49,50]$. The setup was tested on bulk $\mathrm{Au}$ and on a $107 \mathrm{~nm} \mathrm{Au}$ layer on the $\mathrm{Bi}_{2} \mathrm{Se}_{3}$ (for both cases the contact electrode and conductive tip were located on the same material). We observed a higher conductivity of the bulk material (quantum size effect) (Figure 3, compare curves a) and b)) and a small photodiode effect of $\mathrm{Au} / \mathrm{Bi}_{2} \mathrm{Se}_{3}$ $(-100 \mathrm{mV})$ due to the AFM illumination (Figure 3, see the intersection of curve $\mathrm{b}$ with the $x$-axis). We also measured $\mathrm{Au}$ layers with a thickness of $53 \mathrm{~nm}$ and $19 \mathrm{~nm}$ (before and after e-beam forced diffusion), and bare $\mathrm{Bi}_{2} \mathrm{Se}_{3}$ (contact placed on the $107 \mathrm{~nm}$ Au layer), see Figure S1, Supporting Information File 1. The curves for each Au thickness at the same area with

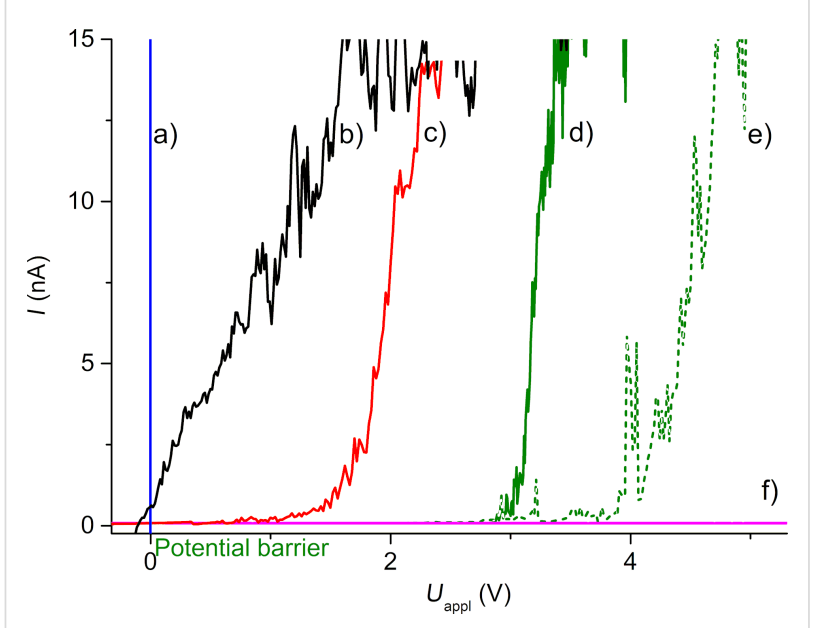

Figure 3: Single-point $I-V$ curves performed during the mechanical contact with the Pt-coated conductive tip on a) bulk Au; b) $107 \mathrm{~nm} \mathrm{Au}$ layer (both contacts on the same layer); c) $53 \mathrm{~nm}$ Au layer; d) and e) $19 \mathrm{~nm}$ Au layer before and after e-beam diffusion; f) cleaved $\mathrm{Bi}_{2} \mathrm{Se}_{3}$. Curves c-f) were measured with the ohmic contact on the $107 \mathrm{~nm} \mathrm{Au}$ layer (see Figure S1, Supporting Information File 1). the best reproducibility are shown in Figure 3. The potential cut-in barrier strongly depends on the Au thickness with values of $1.5 \mathrm{~V}$ for the $53 \mathrm{~nm} \mathrm{Au}$ layer and $3.0 \mathrm{~V}$ for $19 \mathrm{~nm} \mathrm{Au}$ (see Figure 3; curves c, d)). No potential barrier was measurable on $\mathrm{Bi}_{2} \mathrm{Se}_{3}$ up to $6 \mathrm{~V}$.

There is a systematic increase in the potential cut-in barrier for $53 \mathrm{~nm} \mathrm{Au} / \mathrm{Bi}_{2} \mathrm{Se}_{3}$ upon cycling (Figure 4A). The cut-in barrier was less than $1 \mathrm{~V}$ during the first measurement, and above $6 \mathrm{~V}$ for the tenth measurement at the same place. The topography also changed significantly after 10 cycles of $I-V$ measurements. Newly formed perturbations were observed with a height of over $1 \mu \mathrm{m}$ and a FWHM of $2 \mu \mathrm{m}$ (Figure 4B). The changes in the electrical behavior as well as the growth of the perturbations can be explained by the growth of an isolating oxide layer by anodic oxidation. This has also been observed for Si [51,52], $\mathrm{Ti}, \mathrm{Ni}$ or Al [53-55], carbon [56] and organic-inorganic compounds [57]. We suggest, in our case, that $\mathrm{OH}^{-}$or $\mathrm{O}^{-} / \mathrm{O}_{2}^{-}$ions diffuse through our polycrystalline Au layer with many defects (grain boundaries, dislocations) forced by the strong electric field $\left(8 \mathrm{~V} / 53 \mathrm{~nm}\right.$ of Au, i.e., ca. $\left.1.5 \times 10^{8} \mathrm{~V} / \mathrm{m}\right)[35,36]$. At the $\mathrm{Au}-\mathrm{Bi}_{2} \mathrm{Se}_{3}$ interface the oxidation of $\mathrm{Bi}_{2} \mathrm{Se}_{3}$ can occur accompanied by the formation of non-conductive bismuth oxides (optical $E_{\mathrm{g}}=3.31 \mathrm{eV}$ for a $60 \mathrm{~nm} \mathrm{BiO}_{x}$ film [58]). Typically, the thickness of surface oxide layers is much lower (of the order of nanometers for $\mathrm{SiO}_{2}$ on $\left.\mathrm{Si}[51,52]\right)$. In our case it is increased by the electric field and good oxygen mobility in $\mathrm{BiO}_{x}$ due to the formation of charged Bi vacancies $[59,60]$.

This assumption is in good agreement with the observed increase of the cut-in potential barrier upon thinning of the $\mathrm{Au}$ layer (see Figure 3) as a reminiscence of the diffusion limitation of oxygen/hydroxy anions due to the electric field through the polycrystalline Au layer. Bare $\mathrm{Bi}_{2} \mathrm{Se}_{3}$ had no diffusion limits and the $I-V$ curves are not measurable as electrons immediately form isolating $\mathrm{BiO}_{x}$ on the surface. The abovemen-
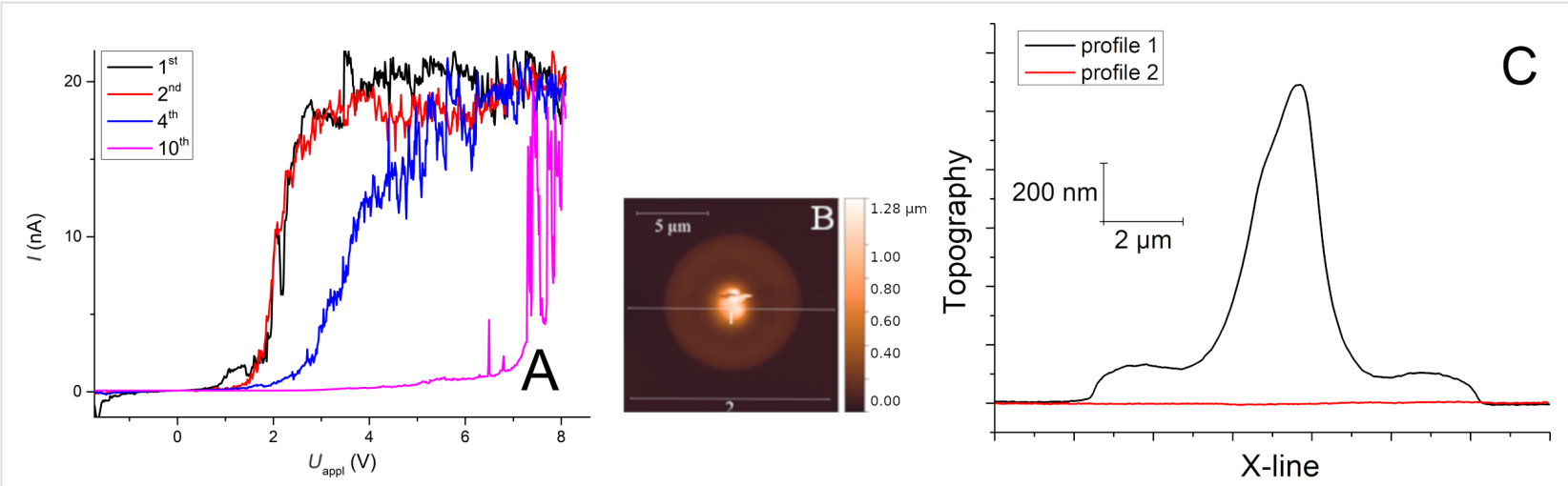

Figure 4: (A) Change of the $I-V$ characteristics for ten repetitions of a single-point and (B) induced changes in the topography and (C) height profiles across a perturbation and a non-affected area (horizontal lines in (B)). 
tioned facts, tentatively summarized as $I-V$ characteristics, are strongly affected by the oxidation of $\mathrm{Bi}_{2} \mathrm{Se}_{3}$. The perturbation with a height of more than $1 \mu \mathrm{m}$ could be easily formed by the oxidation of a highly $\mathrm{O}$-mobile material, e.g., $\mathrm{BiO}_{x}$. This limits the usage of $I-V$ measurements in the static electrical contact of the Schottky barrier in ambient atmosphere to stable materials.

KPFM is an alternative way for mapping the changes in the surface contact potential $[19,20,26]$ and reduces force and time of the tip-sample interaction, which in turn reduces the oxidation of the material. The NIs were embedded by local Au diffusion or the reaction of the Mo layer with the $\mathrm{Bi}_{2} \mathrm{Se}_{3}$ substrate. To enhance the diffusion/reaction rate, we used e-beam irradiation. An area of the $8 \times 10 \mu \mathrm{m}^{2}$ was locally irradiated by an electron beam for different periods of time ( $75 \mathrm{~s} ; 180 \mathrm{~s}$ and $360 \mathrm{~s})$. This resulted in a nanocomposite material consisting of the metal layer locally reacted with $\mathrm{Bi}_{2} \mathrm{Se}_{3}$ support and the original metal layer on the support surface. We were able to compare metallic materials with different thicknesses and determine the highest contrast in the surface contact potential reducing the problem of the diffused interface.

The e-beam-irradiated area exhibits a different SEM signal due to the changes of the chemical composition (Au diffusing into $\mathrm{Bi}_{2} \mathrm{Se}_{3}$ ) and changes in the topography (Figure 5). The same NIs, detected by the AFM (Figure 5), exhibited the topographical features of a few tens of nanometers $(10 \mathrm{~nm}$ in the center and almost $40 \mathrm{~nm}$ at the edges) and changes in the phase contrast, both due to the density decrease of the Au alloy upon reaction with the substrate. All samples were irradiated for a period of $360 \mathrm{~s}$. KPFM demonstrated strong variations of the surface contact potential of NIs (measured in the center of the irradiated area) with respect to the non-irradiated area of the $\mathrm{Au}$ layer (Figure 6). It should be noted, that the edges of the irradiated area are topographically elevated and exhibit a decreased surface potential because of the higher electron irradiation dose at the turning points of the e-beam. A higher dose led to a higher local temperature, which implies an increased formation
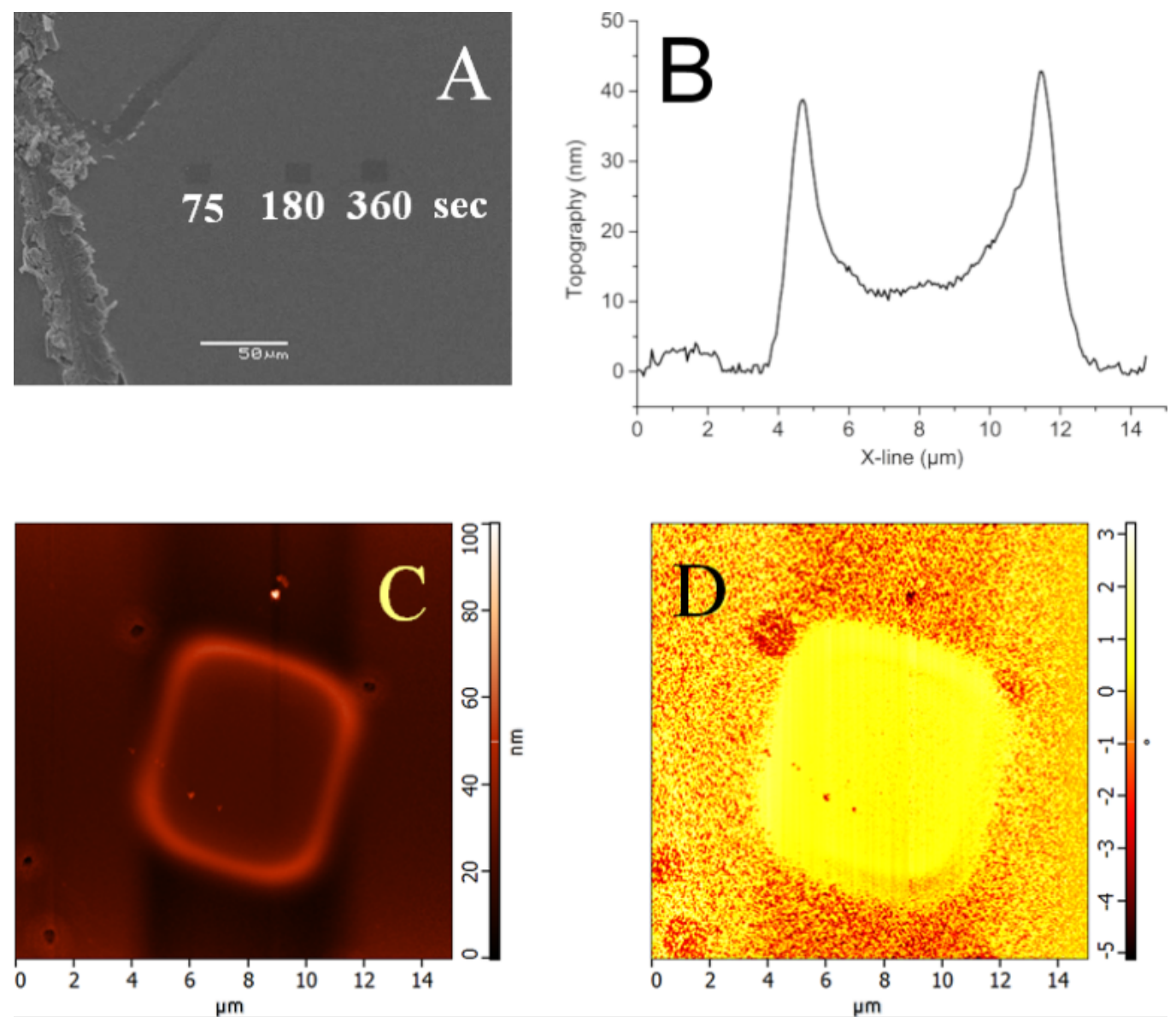

Figure 5: (A) SEM image of the Au layer (33 nm in thickness) on $\mathrm{Bi}_{2} \mathrm{Se}_{3}$ irradiated by the electron beam for different periods of time; (B) topographical profile across the irradiated area taken from (C); (C) topographical AFM and (D) and phase-contrast AFM image of the e-beam-irradiated (360 s) Au layer (33 $\mathrm{nm}$ in thickness) on $\mathrm{Bi}_{2} \mathrm{Se}_{3}$. 

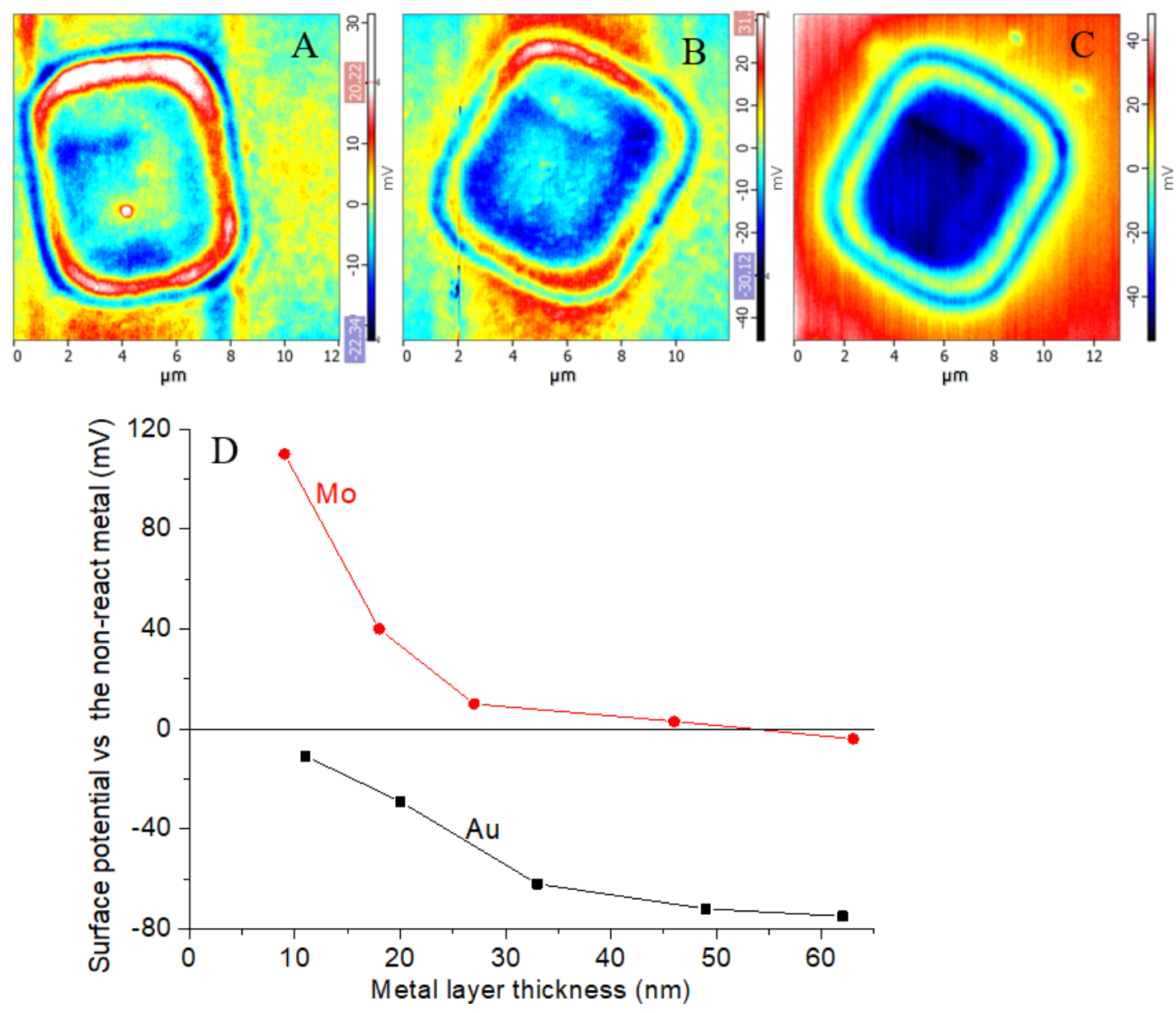

Figure 6: Maps of the surface contact potential measured by means of KPFM for the e-beam formed $\mathrm{Nls}_{\text {on }}$ the $\mathrm{Au}_{\text {layer/Bi }} \mathrm{Se}_{3}$ for different values of Au layer thickness: (A) $12 \mathrm{~nm},(B) 20 \mathrm{~nm}$ (B), and (C) $33 \mathrm{~nm}$; (D) surface potential contrast between irradiated and non-irradiated parts of the metal layers as a function of the layer thickness.

of Au alloy and rims. The comparable so-called "Marangoni effect" was observed in laser-irradiated polymers as described by Lyutakov and co-workers [61].

The NIs formed on the thinnest $\mathrm{Au}(12 \mathrm{~nm})$ exhibited a surface potential signal slightly above the detection limit of KPFM (Figure 6). With increasing thickness of the Au layer there is a higher contrast (Figure 6). The maximum value of the surface potential difference is between -80 and $-90 \mathrm{mV}$ and is connected with the diffusion of $\mathrm{Au}$ into $\mathrm{Bi}_{2} \mathrm{Se}_{3}$. Although the dependence and the values are alike for 1D particles (Figure 2) and for layers (Figure 6), it is difficult to compare them due to the different "substrate" $\left(\mathrm{Bi}_{2} \mathrm{Se}_{3}\right.$ for $1 \mathrm{D}$ particles and nondiffused $\mathrm{Au}$ for the layers).

The Mo layers on $\mathrm{Bi}_{2} \mathrm{Se}_{3}$ reacted to the e-beam irradiation in a different way. The irradiated part of the Mo layer expanded less strongly than the Au layer $(5 \mathrm{~nm}$ at the center, $20 \mathrm{~nm}$ at the edge, see Figure 7 profiles) and the contrast in the surface con- tact potential increased. The most intensive contrast $(109 \mathrm{mV})$ was detected for NIs in the $9 \mathrm{~nm}$ thick Mo layer, whereas almost negligible surface contact potential difference $(-4 \mathrm{mV})$ was detected for the $63 \mathrm{~nm}$ thick Mo layer.

The results of the surface contact potential mapping at the nanoscale were correlated to the macroscopic work functions (WF) of freshly cleaved $\mathrm{Bi}_{2} \mathrm{Se}_{3}$ and $\mathrm{Au}$ or Mo layers (both $30 \mathrm{~nm}$ in thickness). Work functions were measured by surface-sensitive ultraviolet photoelectron spectroscopy (UPS) (Figure 8) employing He I irradiation $(h v=21.22 \mathrm{eV})$ with an information depth up to $3 \mathrm{~nm}$. The work function was determined from UPS spectra as an intersection between the background and the linear extrapolation of the secondary-electron cut-off. We obtained $\mathrm{WF}_{\mathrm{Bi} 2 \mathrm{Se} 3}=5.22 \mathrm{eV}, \mathrm{WF}_{\mathrm{Au} / \mathrm{Bi} 2 \mathrm{Se} 3}=4.79 \mathrm{eV}$, $\mathrm{WF}_{\mathrm{Mo} / \mathrm{Bi} 2 \mathrm{Se} 3}=5.98 \mathrm{eV}$ for $\mathrm{Ar}^{+}$-sputtered samples. The WF increased by $760 \mathrm{meV}$ with the Mo layer, whereas the WF decreased by $-430 \mathrm{meV}$ after sputtering the Au layer onto $\mathrm{Bi}_{2} \mathrm{Se}_{3}$. 

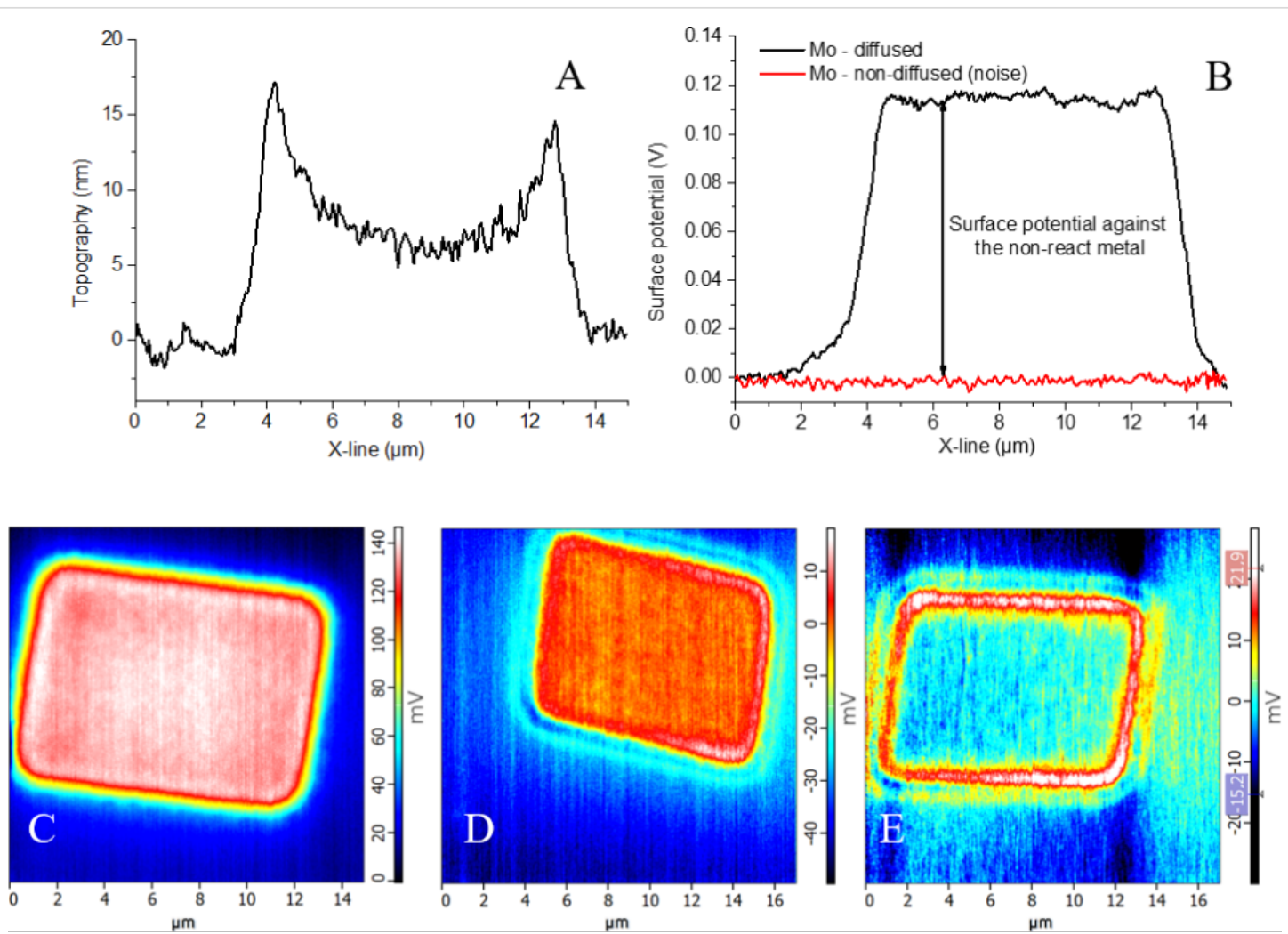

Figure 7: (A) Topographical and (B) surface contact potential profiles of the $9 \mathrm{~nm}$ irradiated Mo layer; maps of the surface contact potential measured by the KPFM for the e-beam formed NIs on the Mo layer/Bi ${ }_{2} \mathrm{Se}_{3}$ for Mo thickness values of (C) $9 \mathrm{~nm}$, (D) $17 \mathrm{~nm}$, and (E) $63 \mathrm{~nm}$.

We can sum up above results as follows:

The Au layer on the $\mathrm{Bi}_{2} \mathrm{Se}_{3}$ surface exhibited lower work function (WF) values than the freshly cleaved $\mathrm{Bi}_{2} \mathrm{Se}_{3}$ surface, measured by means of the UPS ( $4.79 \mathrm{eV}$ vs $5.22 \mathrm{eV})$. This is in good agreement with the decrease of the surface contact potential of the separated $\mathrm{Au}$ particles on $\mathrm{Bi}_{2} \mathrm{Se}_{3}$ detected by the KPFM (limited to $-40 \mathrm{mV}$, see Figure 2C).

The local irradiation of the Au layer on $\mathrm{Bi}_{2} \mathrm{Se}_{3}\left(\mathrm{Ar}^{+}\right.$ions before UPS or SEM electrons during formation of NIs for KPFM measurements) led to a reaction with a substrate, most likely the incorporation of interstitial $\mathrm{Au}$ atoms into the $\mathrm{Bi}_{2} \mathrm{Se}_{3}$ matrix and $\mathrm{Au}$ alloy/compound formation. This material displayed lower density (topographical expansion, Figure 5) and the creation of the defect states (tentatively connected to the shoulder of the UPS edge, see Figure 8, black curve near $17 \mathrm{eV}$ as well as a decrease in the surface contact potential of the Au NIs, see Figure 6).

In the case of Mo the situation is more complex. We were not able to prepare separated Mo 1D particles due to the higher melting temperature of Mo compared to the Au. The thinnest Mo layer led to the highest contrast in the surface contact poten- tial of the NIs (see Figure 7) due to the formation of a thermodynamically more stable $\mathrm{MoSe}_{2}$ layer. The increase in Mo layer thickness led to the presence of the metallic Mo, which is not stable in air and is oxidized within $1 \mathrm{~h}$ at RT [62]. The presence of the $\mathrm{MoO}_{x}$ layer is reflected by the high value of the WF (5.98 eV in this work, Mo $4.3 \mathrm{eV}$ and $\mathrm{MoSe}_{2} 5.65 \mathrm{eV}$ as reported in [63]), which fits better to $\mathrm{MoO}_{x}$ layer after the thermal evaporation $(6.8 \mathrm{eV})$ and after $1 \mathrm{~h}$ oxidation at air at RT $(5.6 \mathrm{eV})$. Partly oxygen-depleted $\mathrm{MoO}_{x}$ exhibited a WF of $6.36 \mathrm{eV}$ [62]. In our case, non-reacted Mo on the stable $\mathrm{MoSe}_{2}$ remains reactive (layered $\mathrm{MoSe}_{2}$ forms a barrier for further Mo diffusion) and Mo reacts with oxygen to produce $\mathrm{MoO}_{x}$. The UPS information is obtained from the topmost 2-3 nm, i.e., from the oxidized $\mathrm{MoO}_{x}$ layer (30 $\mathrm{nm}$ of Mo was sputtered on the $\mathrm{Bi}_{2} \mathrm{Se}_{3}$ for UPS measurements). The $9 \mathrm{~nm}$ Mo layer after SEM electron irradiation led to the formation of $\mathrm{MoSe}_{2}$ (through the reduction of $\mathrm{MoO}_{x}$ in vacuum to Mo and subsequent reaction with $\mathrm{Bi}_{2} \mathrm{Se}_{3}$ ) and these NIs revealed the highest contrast in contact potential (Figure 7). When the thickness of the Mo layer (17 and $63 \mathrm{~nm}$, see Figure 7) is increased, not all Mo reacts to $\mathrm{MoSe}_{2}$ and there is a cover layer of $\mathrm{MoO}_{x}$. If the $\mathrm{MoO}_{x}$ layer is irradiated by electrons under the same conditions as the thinnest Mo layer, there will be a partial oxygen depletion as well [62]. However, the long distance from the 
$\mathrm{Bi}_{2} \mathrm{Se}_{3}$ substrate hinders a reaction (the sample exhibits a sandwich structure of reactive $\mathrm{Bi}_{2} \mathrm{Se}_{3}$ /isolating $\mathrm{MoSe}_{2}$ /isolating Mo and $\mathrm{MoO}_{x}$ /reactive oxygen-depleted $\mathrm{MoO}_{x}$ ). This is further reflected in a low contrast in KPFM measurements, as only nonirradiated and re-oxidized (due to ambient atmosphere) $\mathrm{MoO}_{x}$ layers are measured. Even if $\mathrm{MoSe}_{2}$ is formed at the $\mathrm{MoO}_{x} /$ $\mathrm{Bi}_{2} \mathrm{Se}_{3}$ interface, its presence is hidden for both UPS (low information depth) and KPFM (electrons prefer a more conductive path in the $\mathrm{Mo} / \mathrm{MoO}_{x}$ layer).

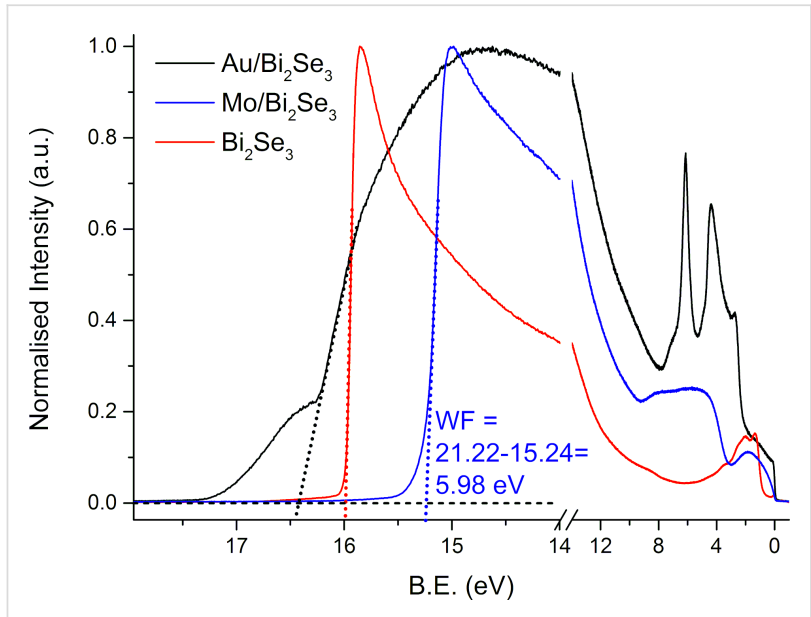

Figure 8: UPS data for $\mathrm{Bi}_{2} \mathrm{Se}_{3}$; Mo or Au layers on the top of the $\mathrm{Bi}_{2} \mathrm{Se}_{3}$ cleaned by the $\mathrm{Ar}^{+}$sputtering excited by the $\mathrm{He} \mathrm{I}$ $(h \mathrm{v}=21.22 \mathrm{eV})$.

The applicability of the partial diffusion of the Au layers was tested by the photodiffusion of the $20 \mathrm{~nm}$ Au layer into $\mathrm{Bi}_{2} \mathrm{Se}_{3}$ by UV source through a Ronchi ruling $[64,65]$. The illuminated $\mathrm{Au}-\mathrm{Bi}_{2} \mathrm{Se}_{3}$ exhibited a periodical pattern of the surface potential with an amplitude of $20 \mathrm{mV}$ (Figure 9). This value is slightly lower in contrast to the NIs obtained by e-beam irradiation of the $20 \mathrm{~nm} \mathrm{Au}$ layer (decrease $29 \mathrm{mV}$ ), and could be connected with the partial lateral diffusion of the heat or $\mathrm{Au}$ atoms/ions. In this way, the possibility to prepare a material with patterned surface contact potential at the macroscopic scale was demonstrated.

\section{Conclusion}

We demonstrated local changes of the work function/surface contact potential as a consequence of metal nanoinclusions on the surface of $\mathrm{Bi}_{2} \mathrm{Se}_{3}$. These Schottky barriers can be realized in the form of separated metal nanoparticles through dc sputtering, or through the local reaction/diffusion of a metallic layer irradiated with electrons or UV photons. The value of the work function barrier is measurable by KPFM at the nanoscale even in ambient atmosphere and, most importantly, it strongly depends on the size of the metal particles. The results are in good agreement with the macroscopic UPS results $\left(1 \mathrm{~mm}^{2}\right)$ obtained in UHV. The investigation of the Schottky barrier in ambient atmosphere is limited to noble metals only, as the Mo nanolayer reacts with oxygen forming $\mathrm{MoO}_{x}$ at RT within a few hours. We therefore conclude that KPFM has the following limitations: i) Only oxidization-resistant metals/semiconductor nanoinclusions can be used. Transition metals react with air and, thus, vacuum equipment is required for the preparation, transport and measurement. ii) The conductive AFM tip has to be coated with a mechanically hard and non-reacting layer as TiN. Typical Au or Pt coatings need to be avoided because the coating might diffuse into the material forced by the electric field during the interaction. iii) The $I-V$ characteristics can be affected by oxidation and perturbations with a height above $1 \mu \mathrm{m}$ can be easily formed by oxidation of a highly O-mobile material such as $\mathrm{BiO}_{x}$.

\section{Supporting Information}

\section{Supporting Information File 1}

Scheme of electric circuit.

[https://www.beilstein-journals.org/bjnano/content/ supplementary/2190-4286-10-138-S1.pdf]
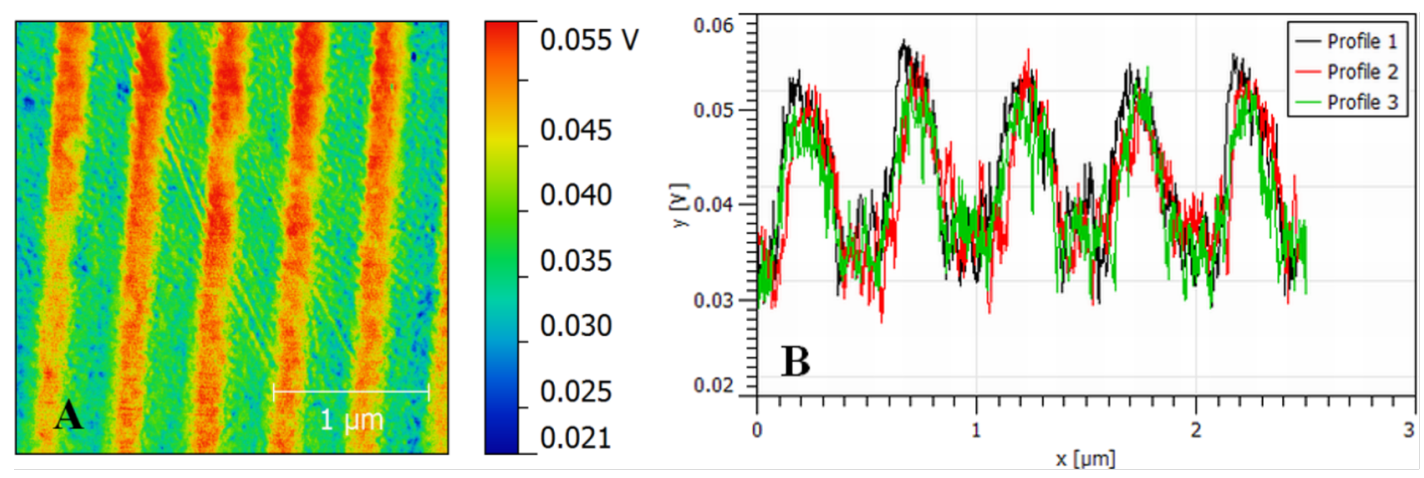

Figure 9: (A) Changes of the surface potential in the pattern after UV photodiffusion of $\mathrm{Au}(20 \mathrm{~nm})$ into $\mathrm{Bi}_{2} \mathrm{Se}_{3}$ and $(\mathrm{B})$ three line profiles. 


\section{Acknowledgements}

The financial support from the Grant Agency of the Czech Republic (GA CR), projects No. 16-07711S and No. 19-11814S is greatly appreciated. The work was supported from European Regional Development Fund-Project "Modernization and upgrade of the CEMNAT (No. CZ.02.1.01/0.0/0.0/16_013/ 0001829)".

\section{ORCID ${ }^{\circledR}$ iDs}

Petr Knotek - https://orcid.org/0000-0003-2407-4947

Tomáš Plecháček - https://orcid.org/0000-0002-9972-4177

Jan Smolík - https://orcid.org/0000-0002-4897-2453

Filip Dvořák - https://orcid.org/0000-0003-1466-6121

Čestmír Drašar - https://orcid.org/0000-0002-5645-5683

\section{References}

1. Slack, G. A. CRC Handbook of Thermoelectrics; CRC Press: Boca Raton, FL, U.S.A., 1995; p 407.

2. Hicks, L. D.; Dresselhaus, M. S. Phys. Rev. B 1993, 47, 12727-12731. doi:10.1103/physrevb.47.12727

3. Liu, W.; Yan, X.; Chen, G.; Ren, Z. Nano Energy 2012, 1, 42-56. doi:10.1016/j.nanoen.2011.10.001

4. Li, H.; Tang, X.; Zhang, Q.; Uher, C. Appl. Phys. Lett. 2009, 94, 102114. doi:10.1063/1.3099804

5. Han, M.-K.; Ahn, K.; Kim, H.; Rhyee, J.-S.; Kim, S.-J. J. Mater. Chem. 2011, 21, 11365-11370. doi:10.1039/c1jm10163c

6. Liu, D.-W.; Li, J.-F.; Chen, C.; Zhang, B.-P. J. Electron. Mater. 2011, 40, 992-998. doi:10.1007/s11664-010-1476-x

7. Faleev, S. V.; Léonard, F. Phys. Rev. B 2008, 77, $214304-214312$. doi:10.1103/physrevb.77.214304

8. Zebarjadi, M.; Esfarjani, K.; Shakouri, A.; Bahk, J. H.; Bian, Z. X.; Zeng, G.; Bowers, J.; Lu, H.; Zide, J.; Gossard, A. Appl. Phys. Lett. 2009, 94, 202105. doi:10.1063/1.3132057

9. Narducci, D.; Selezneva, E.; Cerofolini, G.; Frabboni, S.; Ottaviani, G. J. Solid State Chem. 2012, 193, 19-25. doi:10.1016/j.jssc.2012.03.032

10. Kulbachinskii, V. A.; Kytin, V. G.; Popov, M. Y.; Buga, S. G.; Stepanov, P. B.; Blank, V. D. J. Solid State Chem. 2012, 193, 64-70. doi:10.1016/j.jssc.2012.03.065

11. Popov, M.; Buga, S.; Vysikaylo, P.; Stepanov, P.; Skok, V.; Medvedev, V.; Tatyanin, E.; Denisov, V.; Kirichenko, A.; Aksenenkov, V.; Blank, V. Phys. Status Solidi A 2011, 208, 2783-2789. doi:10.1002/pssa.201127075

12. Park, D.-H.; Kim, M.-Y.; Oh, T.-S. Curr. Appl. Phys. 2011, 11, S41-S45. doi:10.1016/j.cap.2011.07.007

13. Li, F.; Huang, X.; Sun, Z.; Ding, J.; Jiang, J.; Jiang, W.; Chen, L. J. Alloys Compd. 2011, 509, 4769-4773. doi:10.1016/j.jallcom.2011.01.155

14. Li, J.-F.; Liu, J. Phys. Status Solidi A 2006, 203, 3768-3773. doi:10.1002/pssa.200622011

15. Xiong, Z.; Chen, X.; Huang, X.; Bai, S.; Chen, L. Acta Mater. 2010, 58, 3995-4002. doi:10.1016/j.actamat.2010.03.025

16. Dou, Y. C.; Qin, X. Y.; Li, D.; Li, L. L.; Zou, T. H.; Wang, Q. Q. J. Appl. Phys. 2013, 114, 044906. doi:10.1063/1.4817074

17.Zou, T. H.; Qin, X. Y.; Li, D.; Ren, B. J.; Sun, G. L.; Dou, Y. C.; Li, Y. Y.; Li, L. L.; Zhang, J.; Xin, H. X. J. Appl. Phys. 2014, 115, 053710. doi:10.1063/1.4864220
18. Ko, D.-K.; Kang, Y.; Murray, C. B. Nano Lett. 2011, 11, 2841-2844. doi:10.1021/nl2012246

19. Agarwal, K.; Kaushik, V.; Varandani, D.; Dhar, A.; Mehta, B. R. J. Alloys Compd. 2016, 681, 394-401. doi:10.1016/j.jallcom.2016.04.161

20. Agarwal, K.; Mehta, B. R. J. Appl. Phys. 2014, 116, 083518. doi:10.1063/1.4894145

21. Singh, B.; Mehta, B. R.; Varandani, D.; Govind; Narita, A.; Feng, X.; Müllen, K. J. Appl. Phys. 2013, 113, 203706. doi:10.1063/1.4807411

22. Miwa, K.; Salleh, F.; Ikeda, H. Makara J. Technol. 2013, 17, 17-20. doi:10.7454/mst.v17i1.1922

23. Muñoz-Rojo, M.; Caballero-Calero, O.; Martín-González, M. Appl. Phys. Lett. 2013, 103, 183905. doi:10.1063/1.4826684

24. Olaya, D.; Hurtado-Morales, M.; Gómez, D.; Castañeda-Uribe, O. A.; Juang, Z.-Y.; Hernández, Y. 2D Mater. 2017, 5, 011004. doi:10.1088/2053-1583/aa90d8

25. Durcan, C. A.; Balsano, R.; LaBella, V. P. J. Appl. Phys. 2014, 116, 023705. doi:10.1063/1.4889851

26. Vanis, J.; Zelinka, J.; Zeipl, R.; Jelinek, M.; Kocourek, T.; Remsa, J.; Navratil, J. J. Electron. Mater. 2016, 45, 1734-1739. doi:10.1007/s11664-015-4193-7

27. Klimovskikh, I. I.; Sostina, D.; Petukhov, A.; Rybkin, A. G.; Eremeev, S. V.; Chulkov, E. V.; Tereshchenko, O. E.; Kokh, K. A.; Shikin, A. M. Sci. Rep. 2017, 7, 45797. doi:10.1038/srep45797

28. Yamasaka, S.; Nakamura, Y.; Ueda, T.; Takeuchi, S.; Sakai, A. Sci. Rep. 2015, 5, 14490. doi:10.1038/srep14490

29. Bala, M.; Gupta, S.; Tripathi, T. S.; Varma, S.; Tripathi, S. K.; Asokan, K.; Avasthi, D. K. RSC Adv. 2015, 5, 25887-25895. doi:10.1039/c5ra01000d

30. Knotek, P.; Chanova, E.; Rypacek, F. Mater. Sci. Eng., C 2013, 33, 1963-1968. doi:10.1016/j.msec.2013.01.006

31. Cermak, P.; Ruleova, P.; Holy, V.; Prokleska, J.; Kucek, V.; Palka, K.; Benes, L.; Drasar, C. J. Solid State Chem. 2018, 258, 768-775. doi:10.1016/j.jssc.2017.12.009

32. Knotek, P.; Tichý, L. Thin Solid Films 2009, 517, 1837-1840. doi:10.1016/j.tsf.2008.09.041

33. Knotek, P.; Tasseva, J.; Petkov, K.; Kincl, M.; Tichy, L. Thin Solid Films 2009, 517, 5943-5947. doi:10.1016/j.tsf.2009.04.038

34. Das, S.; Zazpe, R.; Prikryl, J.; Knotek, P.; Krbal, M.; Sopha, H.; Podzemna, V.; Macak, J. M. Electrochim. Acta 2016, 213, 452-459. doi:10.1016/j.electacta.2016.07.135

35. Glatzel, T.; Sadewasser, S.; Lux-Steiner, M. C. Appl. Surf. Sci. 2003, 210, 84-89. doi:10.1016/s0169-4332(02)01484-8

36. Melitz, W.; Shen, J.; Kummel, A. C.; Lee, S. Surf. Sci. Rep. 2011, 66, 1-27. doi:10.1016/j.surfrep.2010.10.001

37. Knotek, P.; Tichy, L.; Kutalek, P. Thin Solid Films 2015, 594, 67-73. doi:10.1016/j.tsf.2015.09.055

38. Knotek, P.; Vlcek, M.; Kincl, M.; Tichy, L. Thin Solid Films 2012, 520, 5472-5478. doi:10.1016/j.tsf.2012.03.116

39. Axt, A.; Hermes, I. M.; Bergmann, V. W.; Tausendpfund, N.; Weber, S. A. L. Beilstein J. Nanotechnol. 2018, 9, 1809-1819. doi:10.3762/bjnano.9.172

40. Sadewasser, S.; Nicoara, N.; Solares, S. D. Beilstein J. Nanotechnol. 2018, 9, 1272-1281. doi:10.3762/bjnano.9.119

41. Rezek, B.; Stehlik, S. Chapter 10 - Surface potential of nanodiamonds investigated by KPFM. In Nanodiamonds; Arnault, J.-C., Ed.; Elsevier: Amsterdam, Netherlands, 2017; pp 273-300. doi:10.1016/b978-0-32-343029-6.00011-8

42. Watanabe, T.; Fujihira, M. Ultramicroscopy 2009, 109, 1035-1039. doi:10.1016/j.ultramic.2009.03.047 
43. Zeng, T.-W.; Hsu, F.-C.; Tu, Y.-C.; Lin, T.-H.; Su, W.-F. Chem. Phys. Lett. 2009, 479, 105-108. doi:10.1016/j.cplett.2009.07.104

44. Yamauchi, T.; Tabuchi, M.; Nakamura, A. Appl. Phys. Lett. 2004, 84, 3834-3836. doi:10.1063/1.1745110

45. Sasahara, A.; Pang, C. L.; Onishi, H. J. Phys. Chem. B 2006, 110, 17584-17588. doi:10.1021/jp063665h

46. Sasahara, A.; Hiehata, K.; Onishi, H. Catal. Surv. Asia 2009, 13, 9-15. doi:10.1007/s10563-009-9062-z

47. Lide, D. R. Handbook of Chemistry and Physics, 84th ed.; CRC Press: Boca Raton, FL, U.S.A., 2003.

48. Nanomaterials: Synthesis, Properties and Applications; J. W. Arrowsmith, Ltd.: Bristol, United Kingdom, 1996.

49. Lee, H.; Keun Lee, Y.; Nghia Van, T.; Young Park, J. Appl. Phys. Lett. 2013, 103, 173103. doi:10.1063/1.4826140

50. Tedesco, J. L.; Rowe, J. E.; Nemanich, R. J. J. Appl. Phys. 2009, 105, 083721. doi:10.1063/1.3100212

51. Avouris, P.; Martel, R.; Hertel, T.; Sandstrom, R. Appl. Phys. A: Mater. Sci. Process. 1998, 66, S659-S667. doi:10.1007/s003390051218

52. Tello, M.; Garcia, R. Appl. Phys. Lett. 2001, 79, 424-426. doi:10.1063/1.1385582

53. Irmer, B.; Kehrle, M.; Lorenz, H.; Kotthaus, J. P. Appl. Phys. Lett. 1997, 71, 1733-1735. doi:10.1063/1.120019

54. Fang, T.-H.; Chen, K.-J. Mater. Trans. 2007, 48, 471-475. doi:10.2320/matertrans.48.471

55. Shingubara, S.; Murakami, Y.; Morimoto, K.; Takahagi, T. Surf. Sci. 2003, 532-535, 317-323. doi:10.1016/s0039-6028(03)00433-3

56. Chuang, M.-C.; Chien, H.-M.; Chain, Y.-H.; Chi, G.-C.; Lee, S.-W.; Woon, W. Y. Carbon 2013, 54, 336-342. doi:10.1016/j.carbon.2012.11.045

57. Baumgärtel, T.; von Borczyskowski, C.; Graaf, H. Beilstein J. Nanotechnol. 2013, 4, 218-226. doi:10.3762/bjnano.4.22

58. Leontie, L.; Caraman, M.; Alexe, M.; Harnagea, C. Surf. Sci. 2002, 507-510, 480-485. doi:10.1016/s0039-6028(02)01289-x

59. Zhong, G.; Wang, Y.; Dai, Z.; Wang, J.; Zeng, Z. Phys. Status Solidi B 2009, 246, 97-101. doi:10.1002/pssb.200844271

60. Torruella, P.; Coll, C.; Martín, G.; López-Conesa, L.; Vila, M.; Díaz-Guerra, C.; Varela, M.; Ruiz-González, M. L.; Piqueras, J.; Peiró, F.; Estradé, S. J. Phys. Chem. C 2017, 121, 24809-24815. doi:10.1021/acs.jpcc.7b06310

61. Lyutakov, O.; Huttel, I.; Siegel, J.; Švorčík, V. Appl. Phys. Lett. 2009, 95, 173103. doi:10.1063/1.3254210

62. Irfan, I.; James Turinske, A.; Bao, Z.; Gao, Y. Appl. Phys. Lett. 2012, 101, 093305. doi:10.1063/1.4748978

63. Keszler, D. A.; Wager, J. F. Novel Materials Development for Polycrystalline Thin-Film Solar Cells: Final Subcontract Report, 26 July 2004--15 June 2008; Office of Scientific and Technical Information (OSTI), 2008; pp 1-16. doi:10.2172/942065

64. Balakrishnan, M.; Kozicki, M. N.; Poweleit, C. D.; Bhagat, S.; Alford, T. L.; Mitkova, M. J. Non-Cryst. Solids 2007, 353, 1454-1459. doi:10.1016/j.jnoncrysol.2006.09.071

65. Adam, J.-L.; Zhang, X., Eds. Woodhead Publishing Series in Electronic and Optical Materials; Elsevier: Amsterdam, Netherlands, 2014.

\section{License and Terms}

This is an Open Access article under the terms of the Creative Commons Attribution License

(http://creativecommons.org/licenses/by/4.0). Please note that the reuse, redistribution and reproduction in particular requires that the authors and source are credited.

The license is subject to the Beilstein Journal of Nanotechnology terms and conditions:

(https://www.beilstein-journals.org/bjnano)

The definitive version of this article is the electronic one which can be found at:

doi:10.3762/bjnano. 10.138 